\title{
Analysis of Parameters for Vehicles M2 and M3 Category - Case Study Republic of Croatia
}

DOI: https://doi.org/10.7307/ptsm.2020.4

\author{
Julijan Jurak ${ }^{1}$, Marko Slavulj ${ }^{1}$, Marko Emanović ${ }^{2}$, Matija Sikirić ${ }^{1}$ \\ University of Zagreb, Faculty of Transport and Traffic Sciences ${ }^{1}$; Center for Vehicles of Croatia (CVH ${ }^{2}$
}

\section{Keywords:}

Buses

Age of buses

Number of buses

Influence

\begin{abstract}
Vehicles category can be separated into two main categories, $\mathrm{M}$ and $\mathrm{N}$ category. $\mathrm{M}$ categories represent motor vehicles which are used for passenger transport, and $\mathrm{N}$ category is used for freight transport. This paper will present one sub-category of M category (M2 and M3 category). M2 and M3 categories are motor vehicles which have more than 8 passenger seats (without seat for driver), also known as buses. Aim of paper is detect what parameters of buses influence on different variables, mainly considering ages and number of vehicles in Croatia and other countries. The paper consists of introduction, overview of vehicles category in the Republic of Croatia regarding to age, discussion, and conclusion.
\end{abstract}

\section{Introduction}

Vehicles M3 category represent all motor vehicles that can drive more than 8 passengers, without including driver. Other name for M3 category is common know as bus. Buses are widely used for city, intercity and international passenger's lines and for touristic purposes. Mainly owners of buses are companies which means they are used for economic reasons. Knowing that fact, it can be assumed that buses travel more kilometres regarding to vehicles owned by private persons. Also, it can be assumed that are buses generally older than vehicles owned by private persons. Classification of vehicle categories is generated from the ordinance on technical conditions of vehicles in road traffic (M) category, personal vehicles (M1) category, and buses (M2) and (M3) categories. [1]

Vehicle M2category represent motor vehicles for the passenger's transport with more than 8 seats in addition to the driver's seat and a maximum permissible mass $\leq 5000 \mathrm{~kg}$. Vehicle M3 category represent motor vehicles for the passenger's transport, in addition to the driver's seat, have more than 8 seats and a maximum permissible mass $>5000 \mathrm{~kg}$.

Categories M2 and M3 are divided into the following [2]:

- First (I) class - buses with more than 23 seats including the driver, designed for the transport of passengers primarily in a standing position and whose interior is designed to allow passengers to pass quickly through the interior of the vehicle;

- Second (II) class - buses with more than 23 seats including a driver designed primarily for the transport of seated passengers who can also drive standing passengers located only in the aisle space and/or in a space not exceeding the area occupied by two double seats;

- Third (III) class - buses with more than 23 seats including a driver designed to transport passengers in a seated position only;

- A class - buses with a maximum of 23 seats or less including a driver designed to transport passengers in sitting and standing positions;

- B class - buses with a maximum of 23 seats or less including a driver designed to transport passengers in a sitting position only. 
Furthermore, will be presented and analysed the parameters that include the age of the vehicle (M3) category, the number of buses, as well as the display of the average annual distance travelled in kilometres.

\section{Overview of vehicles category in the Republic of Croatia regarding to age}

Period of 5 years was considered regarding to the average age of vehicles in the Republic of Croatia for the category of vehicles (M3), more precisely from 2014 to 2019. In the observed time period, the largest number of vehicles for the observed (M3) category was recorded in 2019 and it amounted to 5375 vehicles, where the average age was 11,55 years, which is also the lowest value for the age of the vehicle. The highest data for the average age was recorded in 2015 and 2017, and for the observed years it was 12,02. Data for other observed years are visible in figure 1. [3]

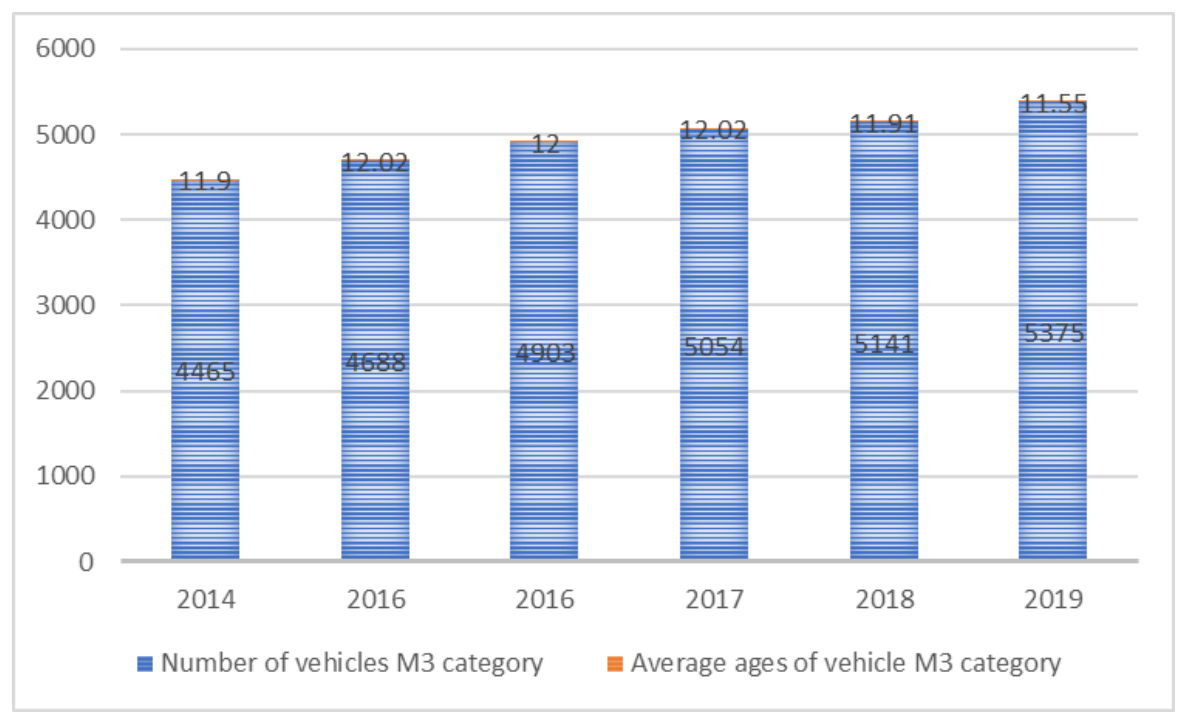

Figure 1. Overview of the total number of vehicles (M3) category and the average age for the period from 2014. to 2019.

Source: [3]

Figure 2 shows the number of vehicles of category (M3) with an age of ten or more. In the year of 2014, a data of 2635 vehicles were recorded, which is also the lowest recorded number of vehicles for the observed age. Through other years, a growth trend is noticeable, which reached its peak in 2019, where a data of 3652 vehicles was recorded. [3]

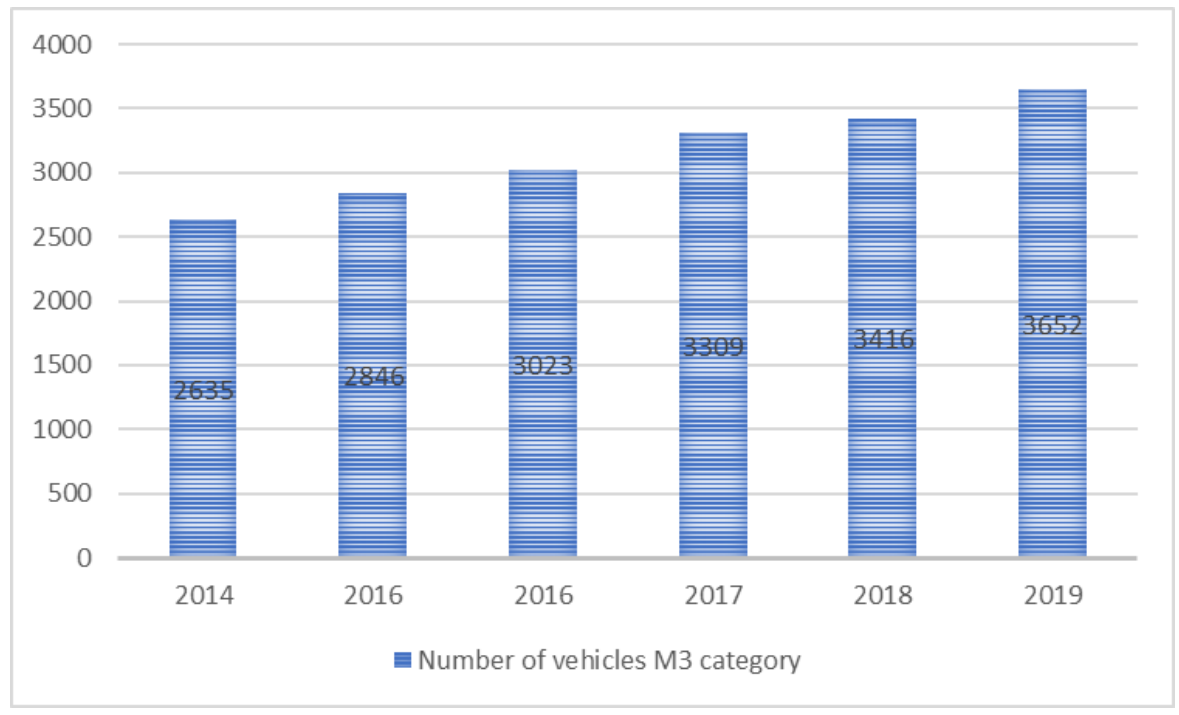


Figure 2. Number of vehicles (M3) of the category with ten or more years of ages for 2014 to 2019 Source: [3]

Figure 3 shows the number of vehicles (M3) of the category with the age from six to nine years. It is noticeable that the lowest number of vehicles was recorded in the last observed year (2019), and it is 622 vehicles. The largest number was recorded in 2015 and it was 1360. After the observed year, a negative trend followed. [3]

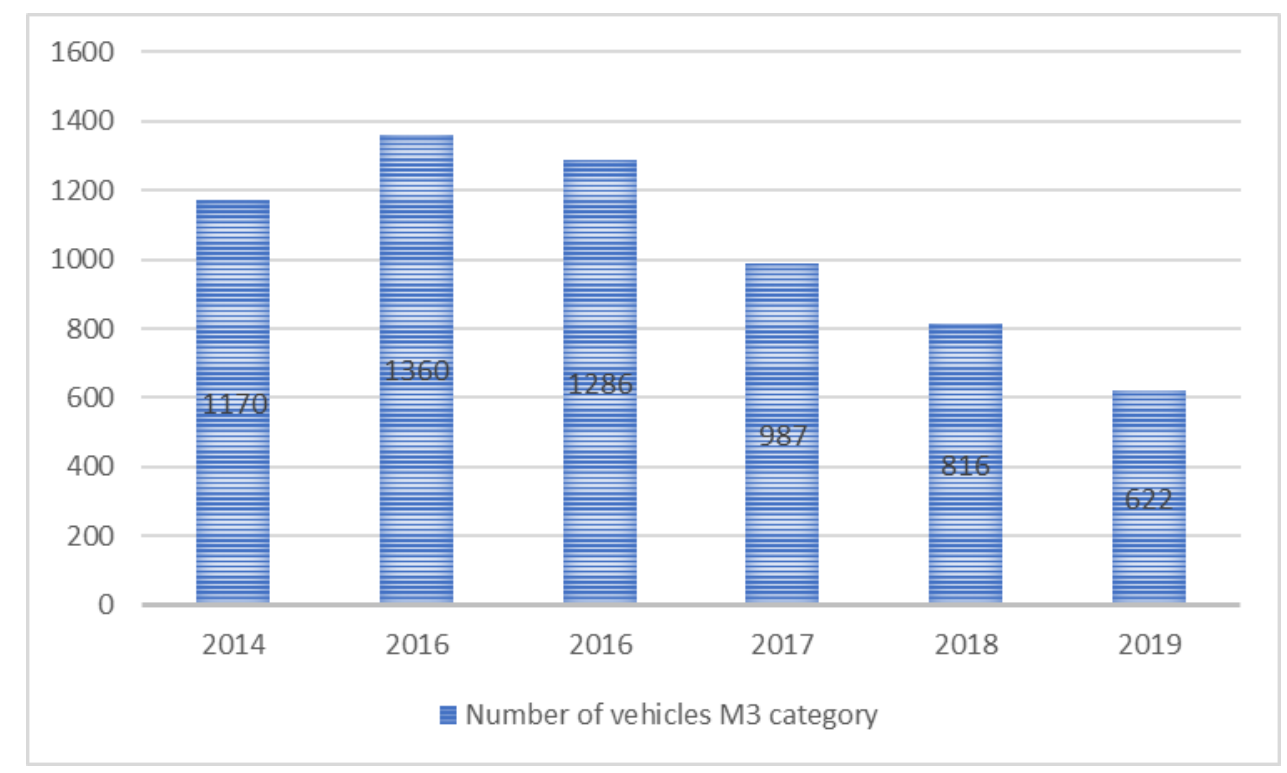

Figure 3. Number of vehicles (M3) of the category from six to nine years of age for 2014 to 2019 Source: [3]

Figure 4 shows statistical data on the age of vehicles from two to five years of age for the observed (M3) category of vehicles. For the observed ages, the lowest data of such vehicles was recorded in 2015 and it was 304 . The highest recorded data was detected in 2019 and it is 644. [3]

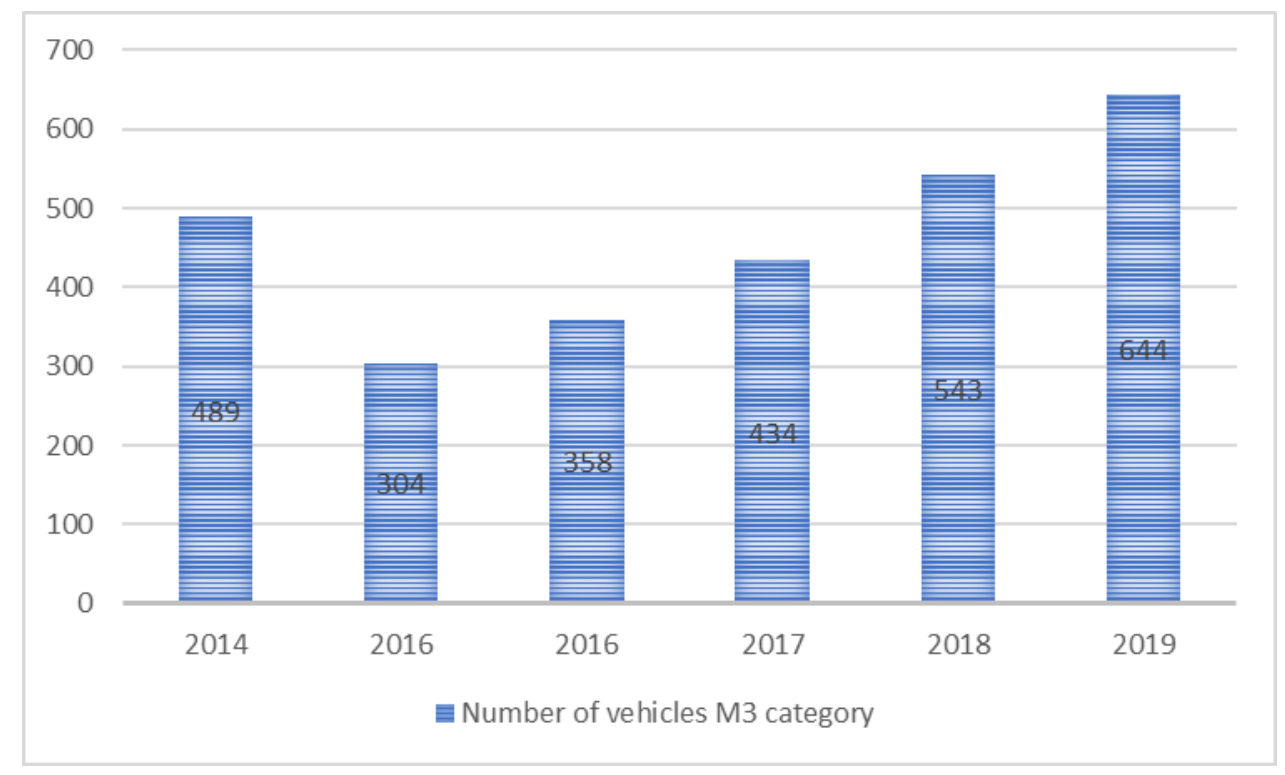

Figure 4. Number of vehicles (M3) of the category from two to five years of age for 2014 to 2019 Source: [3] 
Figure 5 shows statistics for vehicles (M3) of the age category up to one year of age. In the first observed year, in the five-year period, the lowest data was recorded, and it amounted to 171 vehicles. The highest data was recorded in 2019, where it was 457. From 2014 to 2019, the figure shows a growth trend for the observed age of the vehicle. [3]

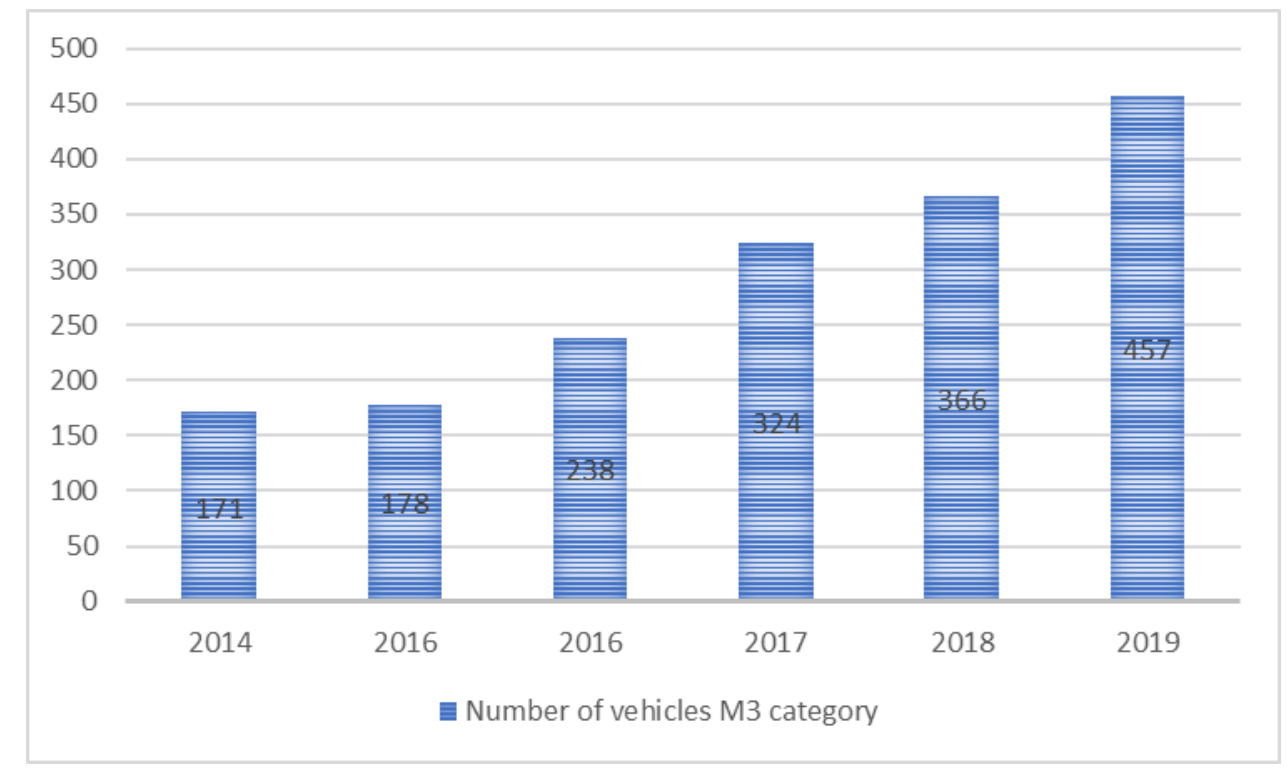

Figure 5. Number of vehicles (M3) of the category up to one year of age for 2014 to 2019 Source: [3]

Figure 6 shown average ages for M3 vehicle category.

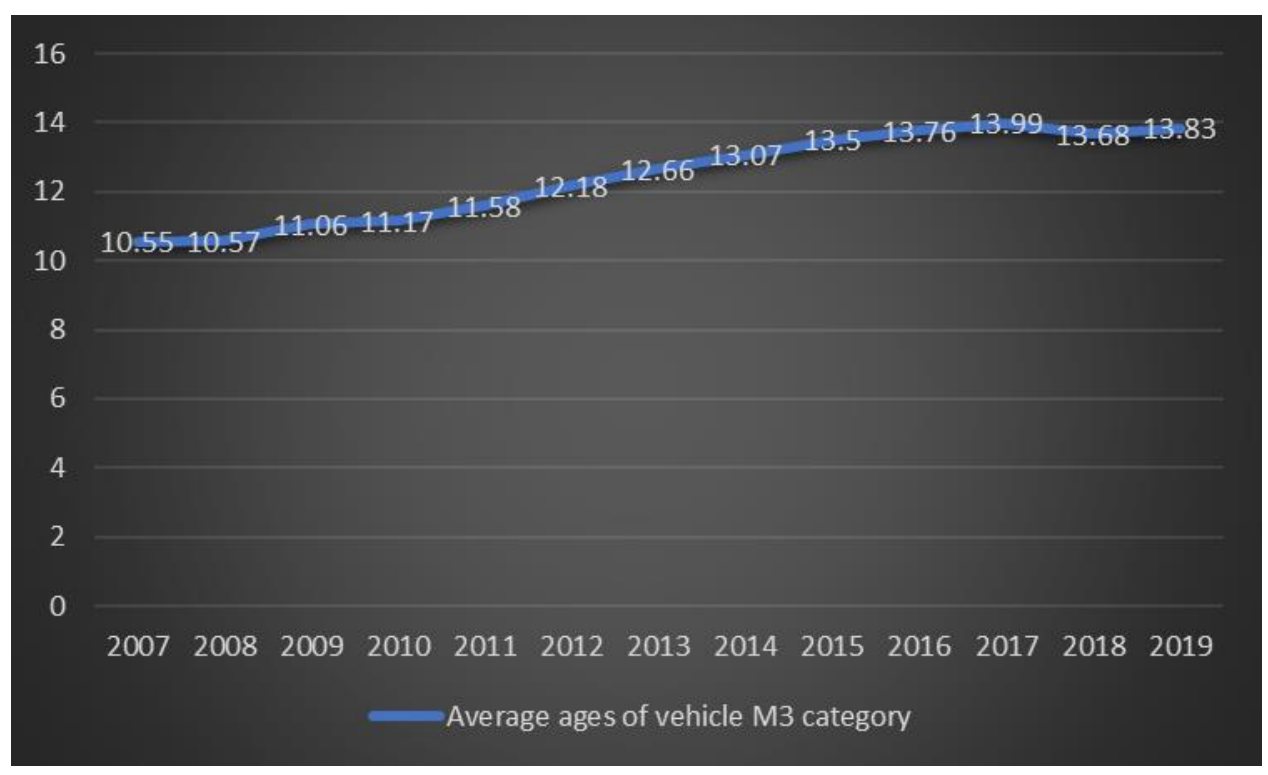

Figure 6. Average ages for M3 vehicle category

Source: [3]

Figure 7 shows average annual travelled kilometres regarding to all vehicle's categories in the Republic of Croatia. 


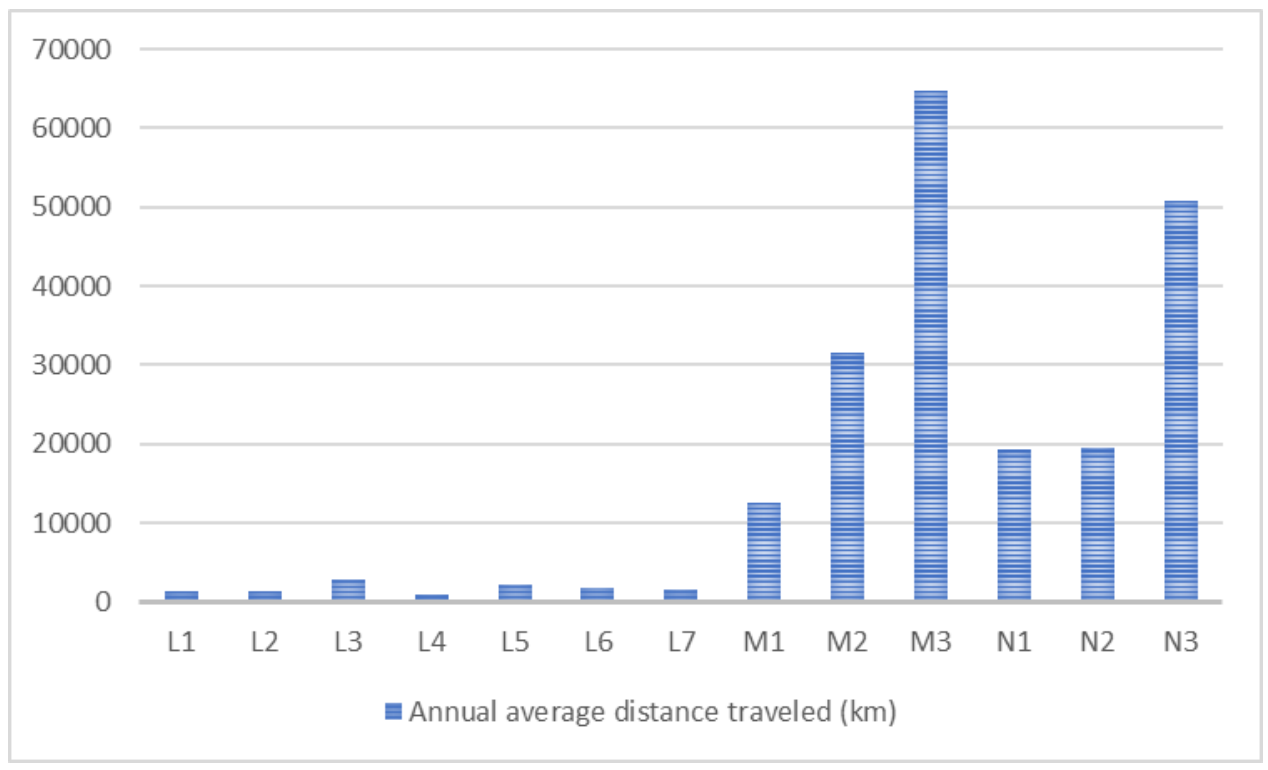

Figure 7. Average annual travelled kilometres regarding to all vehicle's categories in the Republic of Croatia Source: [3]

Figure 8 represent available data regarding to current state of buses fleets in the European Union.

\begin{tabular}{|c|c|c|c|c|c|}
\hline & 2014 & 2015 & 2016 & 2017 & 2018 \\
\hline Austria & 9.585 & 9.679 & 9.825 & 9.956 & 10.037 \\
\hline Belgium & 16.028 & 15.926 & 15,934 & 15.956 & 16.147 \\
\hline Croatia & 4,465 & 4,688 & 4,903 & 5.054 & 5.141 \\
\hline Czech Republic & 19.871 & 19.966 & 20,224 & 20.824 & 21,443 \\
\hline Denmark & 8,802 & 8.858 & 9.052 & 9.077 & 8.982 \\
\hline Estonia & 4,618 & 4,770 & 4,838 & 4,964 & 4,973 \\
\hline Finland & 12,446 & 12,455 & 12,471 & 12,623 & 12,481 \\
\hline France & 89.000 & 90,000 & 91,000 & 91,800 & 92,498 \\
\hline Germany & 77.501 & 78.345 & 78,949 & 79.438 & 80.519 \\
\hline Greece & 24,871 & 22,873 & 23,460 & 24,016 & 27.970 \\
\hline Hungary & 17.384 & 17.681 & 18,143 & 18.594 & 19.091 \\
\hline Ireland & 8,802 & 9.259 & 9.841 & 10.371 & 10,944 \\
\hline Italy & 97.914 & 97.991 & 97.817 & 99.100 & 100,042 \\
\hline Latvia & 4,000 & 4,035 & 4,069 & 4,075 & 4,035 \\
\hline Lithuania & 6,937 & 6.856 & 6.926 & 7.164 & 7.517 \\
\hline Luxembourg & 1.759 & 1.778 & 1.857 & 1.904 & 1.963 \\
\hline Netherlands & 10.145 & 9.409 & 9.741 & 10.069 & 10.055 \\
\hline Poland & 106.057 & 109.844 & 113.139 & 116.090 & 119.471 \\
\hline Portugal & 14,500 & 14,700 & 15.000 & 15.605 & 16.200 \\
\hline Romania & 20.055 & 21.123 & 21,946 & 22,928 & 23,935 \\
\hline Slovakia & 8.879 & 8.944 & 8.810 & 8.955 & 9.078 \\
\hline Slovenia & 2.576 & 2.645 & 2.699 & 2,796 & 2,850 \\
\hline Spain & 59.799 & 60.252 & 61.838 & 63.590 & 64,915 \\
\hline Sweden & 13.992 & 14,114 & 13,890 & 14,421 & 14,378 \\
\hline United Kingdom & 88.638 & 88,186 & 87.778 & 86.607 & 84,391 \\
\hline EUROPEAN UNION & 728,623 & 734,377 & 744,150 & 755,977 & 769,056 \\
\hline Norway & 17.172 & 16,716 & 16.307 & 16.080 & 15.644 \\
\hline Switzerland & 15,713 & 15,684 & 15.602 & 15.431 & 15.435 \\
\hline EFTA & 32,885 & 32,400 & 31.909 & 31.511 & 31.079 \\
\hline Russia & 394,458 & 390.938 & 395.326 & 400.845 & 405.737 \\
\hline Turkey & 211.200 & 217.056 & 220,361 & 221.885 & 218.523 \\
\hline EUROPE & 1.367 .166 & $1.374,771$ & 1.391 .746 & $1.410,218$ & $1,424,395$ \\
\hline
\end{tabular}

Figure 8. Number of registered buses in the countries of European Union from 2014 to 2019.

Source: [4]

\section{Discussion}

Listed figures in the past chapter show interesting data. We can detect growth of buses in the Republic of Croatia and growth of average ages of same buses. Same trend is visible regarding to vehicles older than 10 years. Problem 
is detected with buses older than 6 years and younger than 9 years. In this area the number of buses is decreasing every single year. Good signs are buses younger than 6 years, where is visible larger number of vehicles every single year. Average ages of vehicle M3 category in the past decade shown constantly growth of ages from 10,55 to 13,82 , which is growth more than $20 \%$. If considering annual average distance travelled (in kilometres), M3 categories are first and M2 category is third.

\section{Conclusion}

This paper show interested possible conclusion regarding to buses fleet in Republic of Croatia (M2 and M3 categories). Analysing the number of buses regarding to ages, we can detect that buses are getting older and older with same trend. Also, problem is that buses are vehicle categories that travel most kilometres (almost 4 times regarding to private cars). By comparing to other countries in the European Union, it can be seen that are growing number of buses in almost all countries (approximately $5 \%$ in the last five years), while in Croatia that number is more than $10 \%$ which can be justify by becoming part of European Union which which made it possible to procure cheaper buses from most developed countries. Analyzing that data, two conclusions can be determined. Fist is constant growth of buses in Croatia and other countries, and second is constant growth of older bus fleet.

\section{References}

[1] Bošković. I., “Tehnički pregledi vozila iz perspektive pravila o tržišnom natjecanju”, ZPR 4, vol. 2, no. 2015, pp. 171-205

[2] Hrvatski Autoklub, https://www.hak.hr/vozila/tehnicki-pregledi/popis-stp/, [accessed: november 2020.]

[3] Center for Vehicles of Croatia, https://www.cvh.hr/tehnicki-pregled/stanice-za-tehnicki-pregled/, [accessed: november 2020.]

[4] ACEA European Automobile Manufacturers Association. ACEA Report Vehicles in use Europe 2019. ACEA. Brussels. 2019 